\title{
The Theme and Conceptual Connotation of Academy
}

\section{- Two Essential Issues of the Forum of "The Centennial Friends High School and 100 Years of Education in Chongqing"}

\author{
Xinxian Zhao', Benbin Liang'2, Yongli Tao ${ }^{3}$ \\ ${ }^{1}$ Bayu Culture-Celebrity Research Institute, Chongqing University of Education, Chongqing, China \\ ${ }^{2}$ Department of English, Chongqing University of Education, Chongqing, China \\ ${ }^{3}$ Law School, Chongqing University of Posts and Telecommunications, Chongqing, China \\ Email: 13883061766@163.com
}

Received 27 November 2015; accepted 24 December 2015; published 30 December 2015

Copyright (C) 2015 by authors and Scientific Research Publishing Inc.

This work is licensed under the Creative Commons Attribution International License (CC BY). http://creativecommons.org/licenses/by/4.0/

c) (i) Open Access

\begin{abstract}
This study mainly discusses two essential issues of the forum of "The Centennial Friends High School and 100 Years of Education in Chongqing". Firstly, three research ideas are provided in this paper. Secondly, the paper is also proposed for Headmaster Yang Fang Ling's academic rehabilitation. The paper tries to study the theme and conceptual connotation of academy.
\end{abstract}

\section{Keywords}

Friends High School, Chongqing's Education, Yang Fang Ling, Academic Rehabilitation

\section{Introduction}

Friends High School has a long history of over 100 years. It changed from a church school in 1892 into a private high school in 1925 and then a public school after the reform and opening up from Friends High School academy to Chongqing No.5 middle school. It was closely related with the local education of Chongqing since Chongqing opened the commercial port (1981). Not only does it have more than one hundred years' history, but also it is an important part of local education in Chongqing. Therefore, Friends High School is worth in-depth study. However, from Academic Forum for Friends High School of 100 years and the Education of Chongqing of 100 years, and the existing research on Friends High School, it's seen that the research remains stagnant in historical data digging and arrangement of historical data, and the aspects on the educational thoughts of Yang 
Fang Ling, the former principal, lack deep systematic research.

This article put forward new research ways on Friends High School based on the existing studies. There are three research ideas: Firstly, to investigate the ties between the Centennial Friends High School and the development of education in Chongqing during the last 100 years, on the basis of a comprehensive, macroscopic and overall understanding of the school's history; Secondly, to reflect upon the experiences and lessons in the schooling history of the Centennial Friends High School, on the basis of a forward-looking understanding of the 100 -year history of education development in Chongqing. Thirdly, to reflect over the problems existing in modern China's education and the modernization of Chinese culture, on the basis of a comprehensive cognition of "the Centennial Friends High School and the 100 Years Education in Chongqing". Additionally, the paper is also proposed for Headmaster Yang Fang Ling's academic rehabilitation.

\section{Friends High School and Headmaster Yang Fang Ling}

The theme of the forum for the 122nd anniversary celebration of the Chongqing Friends High School is "The Centennial Friends High School and 100 Years of Education in Chongqing”. This forum topic is a significant academic area that highlights research achievements and has considerable value within the Chinese academic community. Relevant research areas pertain to three key aspects:

To investigate the ties between the Centennial Friends High School and the development of education in Chongqing during the last 100 years, on the basis of a comprehensive, macroscopic and overall understanding of the school's history. From 1892 to 2014, the 122-year-old Friends High School experienced three distinct periods: the late Qing Dynasty (1892-1911), the Republic of China (1911-1949) and socialist China (1949-). These periods parallel the development of education in Chongqing since the port opening of Chongqing in 1891. For a thorough understanding of the academic history of the school, a detailed and comprehensive analysis of relevant literature data must be performed; whereupon, we can gain a real understanding and appreciation of the formation process of this prestigious school's traditions and its profound influence on education development in Chongqing. Additionally, this analysis can help surmount various problems in rehabilitating the school's prestige as an elite school in the 21st century and to live up to this fame in education.

To reflect upon the experiences and lessons in the schooling history of the Centennial Friends High School, on the basis of a forward-looking understanding of the 100 year history of education development in Chongqing. Further research is required to fully grasp this academic idea. We must consider all aspects of the centennial academic development of Chongqing's education, while simultaneously this research topic demands a contextual approach that encompasses an understanding of national educational development trends. In short, a variety of matters related to the 100 years education history of Chongqing are included in this research, such as the schooling history of church schools, private schools, vocational schools, and special education, as well as the adjustment of local schooling policies, the administrative settings for local education, and the macro societal shifts. More importantly, before propelling the development and transformation of local education, we have to understand and familiarize ourselves with the related macroscopic knowledge and literature of the national trends.

To reflect over the problems existing in modern China's education and the modernization of Chinese culture, on the basis of a comprehensive cognition of "the Centennial Friends High School and the 100 Years Education in Chongqing”. The century-long history of Friends High School embodies deep-seated tenets of education, the recognition of which are inseparable from an understanding of the tenets of traditional Chinese education and the spread and influence of Western education and culture in China in the late 19th century. The birth, growth and development of the Centennial Friends High School have all occurred as China has undergone a comprehensive transformation from a time-honored traditional education to a modern education system.

With a profound understanding and appreciation of "the Centennial Friends High School and 100 Years of Education in Chongqing", it becomes possible to carry out deep and continuous explorations into the tenets of education, including the relation between education and social beings, modern personalities, citizens in modern nation-states, and schools of Socialism with Chinese characteristics. A theoretical reflection on the systematic relationship between the century-long history of Friends High School and the 100 years history of education in Chongqing could potentially help decode the true meaning of "the law of education for human beings", as it re- 
lates to the three aforementioned areas and which has long been puzzling educators at all times and in all countries.

The chief academic objective of the 122nd anniversary ${ }^{1}$ forum of Friends High School is very clear: restoration as a traditional elite school in Chongqing. The logical starting point to achieve this aim is a comprehensive exploration, sorting out, research and discussion of the school's century-long history of education and teaching from 1892 to 2014. Friends High School experienced several stages in its history: 33 years as a church school (1892-1925), 25 years as a private school (1925-1950), 40 years as a state-owned school in the name of Chongqing No. 5 Middle School (1951-1992). In 1992, the school was renamed as Friends High School.

A secondary objective of this forum is to provide a more comprehensive rehabilitation for Yang Fang Ling, the school's headmaster from 1911 to 1949. Friends High School gained its traditional reputation as an elite school under the leadership of Headmaster Yang, thus the school's reputation is closely linked to Headmaster Yang's educational ideas, policies, and experiences. In 1983, the Alumni Association of Friends High School resumed operation and exploration of the school's academic history. In 1985, the Chongqing No.2 Intermediate People's Court declared Yang Fang Ling innocent and his reputation was restored. The successful Centennial Celebration of Friends High School in 1994 marked the first strides of substantive research into the school's history. Now in 2014, to greet the school's 120th anniversary and celebrate the research achievements, a book "History of Friends High School" will be published soon; additionally, in the spring, a plan was made to hold an academic forum during the anniversary celebration. This book and forum will restore Headmaster Yang's status as an outstanding educator in the history of modern education in China.

\section{Theme and Conceptual Connotation of Academy}

Yang Fang Ling's academic rehabilitation deserves attention from the academic circle; although he was not an all-powerful politician, he became a prominent and dedicated educator who cultivated a large number of outstanding talents and brought enormous benefits to the people and the nation. Unfortunately, in the 30 years since Yang's political rehabilitation in 1985, not a single academic article on the rectification of Yang's reputation has been promulgated. It seems that Yang is forgotten in the history of modern education in China, further highlighting the need for "academic rehabilitation" in the forum of the school's 122nd anniversary celebration. The unique significance of the academic rehabilitation lies in the inherent provisions of the concept of "academy", the scientific approach of academic research and the ever-lasting influence of academic achievements.

To achieve academic rehabilitation, the basic meaning of academy must first be clearly understood. According to the entry in Ci Hai (the largest comprehensive dictionary in China), "academy" is defined as follows: "It refers to comparatively specialized and systematic learning. In the chapter of Du Xian in Old Book of Tang ( 《旧 唐书・杜暹传》), there is one example: “There seems to be no academy (in Du Xian); in any discussion on the imperial court, (his) remarks are shallow."” (Ci Hai, 1979: p. 1126) Academy in this sense refers to systematic and specialized learning and knowledge, and academic research should be understood as applying systematic and specialized knowledge into the inquiry into problems, and scholarly articles are the written expressions of such activities. Therefore, relevant systematic and specialized knowledge is required to produce high-quality academic articles. The aforementioned forum objectives are all specialized and systematic knowledge areas dedicated to the rectification of Headmaster Yang's reputation.

This understanding of the connotation of "academy" fairly accords with the traditional Chinese academic thoughts. However, at the beginning of the 20th century, the traditional Chinese academic thoughts began to interact and blend with modern western academic thoughts. Under this influence, the connotation of academy in a broad sense became richer and more comprehensive. On basis of the academic knowledge presented in Mr. Zheng Dong's article The characteristics of the concept of academy and the kinetic energy of academic development, the author of this article does a little more elaboration in the following part. All quotes are from this important article.

"In the broad sense, the concept of academy keeps track of people's exploration of the objective world and the academic results of their research and thoughts. Therefore, the concept of academy generalizes the unity of academic research and academic practices. It emphasizes that academy could come into being either in

${ }^{1}$ The exact schooling history is 122 years long. The school's one-hundred anniversary celebrated in 1994 identified the year 1894 as the establishment of the school, which was incorrect. 
the exploration of objective things or through various forms of communication, interaction and fusion. Academy is associated with human practices. The subjects of academy are all types of explorers and thinkers; thoughts, viewpoints, theories and approaches are the embodiment of academy. In essence, academy is an ever-deepening dynamic cognitive process, and it is the result of consensus reached through continuous observation, analysis, reflection, induction and interaction in the cognitive process of human beings. Because of the ever-changing nature of the objective world and the un-limitedness of human practices, academic research never ends.” (Zheng, 2005).

In comparison with the "academy" entry in Ci Hai (1979 edition), the concept of "academy" quoted above covers an interpretation in the broad sense, which is much closer to the actual demands of studying and analyzing problems. The crucial difference between the two definitions lies here: the "academy" entry in Ci Hai explains academy as an ordinary term, succinct and explicit, but with greater emphasis on essentials of the cultural traditions of academy in ancient China. This interpretation of the concept of "academy" in a broad sense ascends to the systematic cognition of modern knowledge, reaching a connotative understanding of academy as a specialized concept, namely, academy as a disciplinary concept. Academy in this broad sense contains the following key elements:

Academy "generalizes the unity of academic research and academic practice"; namely, academy is the behavior of human cognitive activities demonstrated in human's process of learning theories, doing applied practices, and thinking about and studying practical problems";

Academy "could come into being either in the exploration of objective things or through various forms of communication, interaction and fusion"; namely, both the individual learning and thinking of research subjects and the interaction and discussion of research groups are all ways of pondering over problems and academic extensions";

Academy "is associated with human practices". The thinking activities of human beings when considering problems always coexist with various forms of human practices. Therefore, it might not be difficult to understand this notion: academic behaviors in considering problems are "associated with the practice of human activities".

"The subjects of academy are all types of explorers and thinkers; thoughts, viewpoints, theories and approaches are the embodiment of academy". Human beings that consider problems are the subjects of academy, and considering problems is therefore associated with academy; whereas "the embodiment of academy" is mainly the achievements of rational cognition, inseparable with emotions, but it should be a form of reasoning cognition based on logical thinking, rather than a form of essay-like expression of emotions.

After the popular interpretation of the inherent meaning of the concept of academy from the four aspects above, it might be more acceptable to summarize:

"Academy" is "the result of consensus reached through continuous observation, analysis, reflection, induction and interaction in the cognitive process of human beings".

Even though academy's connotation in relation to modern disciplinary knowledge is understood in the general sense, attention must also be paid to the following two quotes regarding two important judgments on the comprehensive grasp of the concept of academy, which might be more beneficial to the evaluation of academic articles.

Emphasis on the characteristic of academy as a research process: "The emphasis on 'academy' is laid on its nature as an academic research process, a process of formation, subnational and development of theories". Emphasis on the essence of academy as the unity of academic research and academic practices: "(This) keeps the balance between 'knowledge (学)' and 'technique (术)', laying equal emphasis on basic theoretical research and applied research. The synthesis and unity of theory and practice are the essence of academy”.

With a basic comprehension of the meaning of academy, Friends High School can proceed in the rehabilitation of the school and its esteemed Headmaster. The erroneous political judgment of Headmaster Yang Fang Ling has been clearly and completely corrected by a copy of official document issued by the court; however, it will not be easy to confirm Headmaster Yang Fang Ling's marvelous contributions to the development of Chi- 
nese education in the 20th century. Even though the theme of the forum for the 122nd anniversary celebration of Friends High School is “The Centennial Friends High School and 100 Years of Education in Chongqing”, only ten-odd articles submitted by the academic circle, alumni and colleagues focused on the academic rehabilitation of Headmaster Yang; however, limited preparation time and the extensive explanatory work needed for the fundamental norms of academy hampered the submission of articles. Nonetheless, the establishment of an academic purpose for this forum signifies a turning point in the restoration of Friends High School as an elite school, and this will surely become a new starting point of research on the history of Friends High School. With strong support from all quarters, we have every reason to do a good job, and to make a great contribution to Chongqing's education, China's education and the education of Socialism with Chinese characteristics.

Finally, for the successful holding of this forum, we would like to express sincere gratitude to the two sponsors, Education Society of Chongqing and Chongqing Friends High School, the Alumni Association of Chongqing Friends High School for their special pains-taking efforts, all authors for their submission of articles, and Chongqing Publishing Group for its strong support in the smooth and successful publication of article collections of the forum.

\section{Acknowledgements}

Finally, for the successful holding of this forum, we would like to express sincere gratitude to the two sponsors, Education Society of Chongqing and Chongqing Friends High School, the Alumni Association of Chongqing Friends High School for their special pains-taking efforts, all authors for their submission of articles, and Chongqing Publishing Group for its strong support in the smooth and successful publication of article collections of the forum.

\section{References}

(1979) Ci Hai. Shanghai: Shanghai Lexicographical Publishing House.

Zheng, D. (2005) Academic Notion and Academic Development. Hebei Academic Journal, 25. 